\title{
Erratum to: Modeling one complete versus triplicate analyses in low template DNA typing
}

\author{
Jianye Ge $\cdot$ Bruce Budowle
}

Received: 24 March 2014 / Accepted: 27 March 2014 /Published online: 6 April 2014

(C) Springer-Verlag Berlin Heidelberg 2014

Erratum to: Int J Legal Med (2014) 128:259-267

DOI 10.1007/s00414-013-0924-6

The original article, unfortunately, contained an error.

Figure 6 (d) was incorrect. The correct figure should be as follows, as the drop in rate would increase with a more sensitive method.

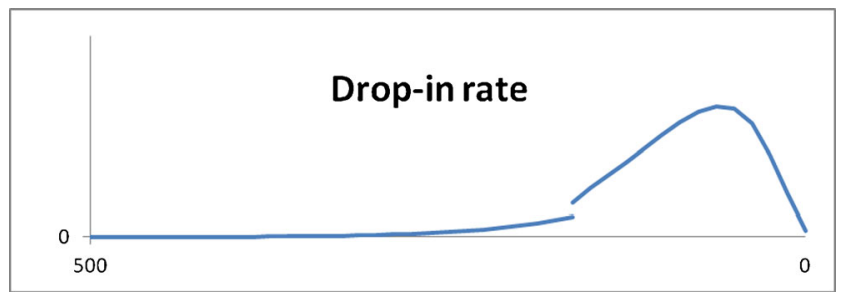

The online version of the original article can be found at http://dx.doi.org/ 10.1007/s00414-013-0924-6.

\footnotetext{
J. Ge $(\bowtie) \cdot$ B. Budowle

Institute of Applied Genetics, Department of Forensics and Investigative Genetics, University of North Texas Health Science

Center, Fort Worth, TX, USA

e-mail: gejianye@gmail.com

B. Budowle

Center of Excellence in Genomic Medicine Research (CEGMR),

King Abdulaziz University, Jeddah, Saudi Arabia
} 